\title{
Research on innovation and practice of university-industry cooperation under Al environment
}

\author{
Hainie Meng ${ }^{1}$ \\ ${ }^{1}$ Guangzhou Nanyang Polytechnic College, Guangzhou 510925, Guangdong, China
}

\begin{abstract}
Along with the deep learning represented by machine learning algorithms in machine vision and speech recognition in areas such as a great success, and cloud computing, big data provide a steady stream of data resources, such as artificial intelligence into the unprecedented rapid development, and is profoundly changing the from all walks of life, but the road of the artificial intelligence + education how to walk, it is lack of system, in view of this the paper together promote cooperation profound research of artificial intelligence, in order to inspire the thinking of artificial intelligence in university-enterprise cooperation promote the deepening of highervocational education and enterprise integration.
\end{abstract}

\section{The introduction}

Intelligence is the new direction of today's social development, but also the newcharacteristics of information development. With the rapid development of artificialintelligence, Internet of Things, big data, cloud computing and other technologies, intelligent products and devices such as smart home, intelligent robots, intelligent toys, intelligent buildings and other intelligent products and devices have brought a hugeimpact on people's way of life and work. In this context, vocational colleges shouldfollow the development of artificial intelligence, promote university-industry cooperationinnovation, build an intelligent university-industry cooperation system, and promote theuniversity-industry cooperation from low level and extensive to high level and precise.

The key to modern university-industry cooperation is to meet the new needs of bothsides in training and using talents, explore the possible effects of artificial intelligence technology in boosting university-industry cooperation innovation, and solve theproblems in the current university-industry cooperation and development.

\section{Main contents of the study}

(1) Artificial intelligence promotes basic research of university-industry cooperation

On the basis of discussing relevant theories and technical support, this paper triesto discuss the new influence and reform brought by artificial intelligence on university-industry cooperation from the aspects of resources of both sides, enterprisementors, school mentors management and cooperation evaluation.The components ofAl promoting school-industry cooperation are shown in Figure 1 below: 


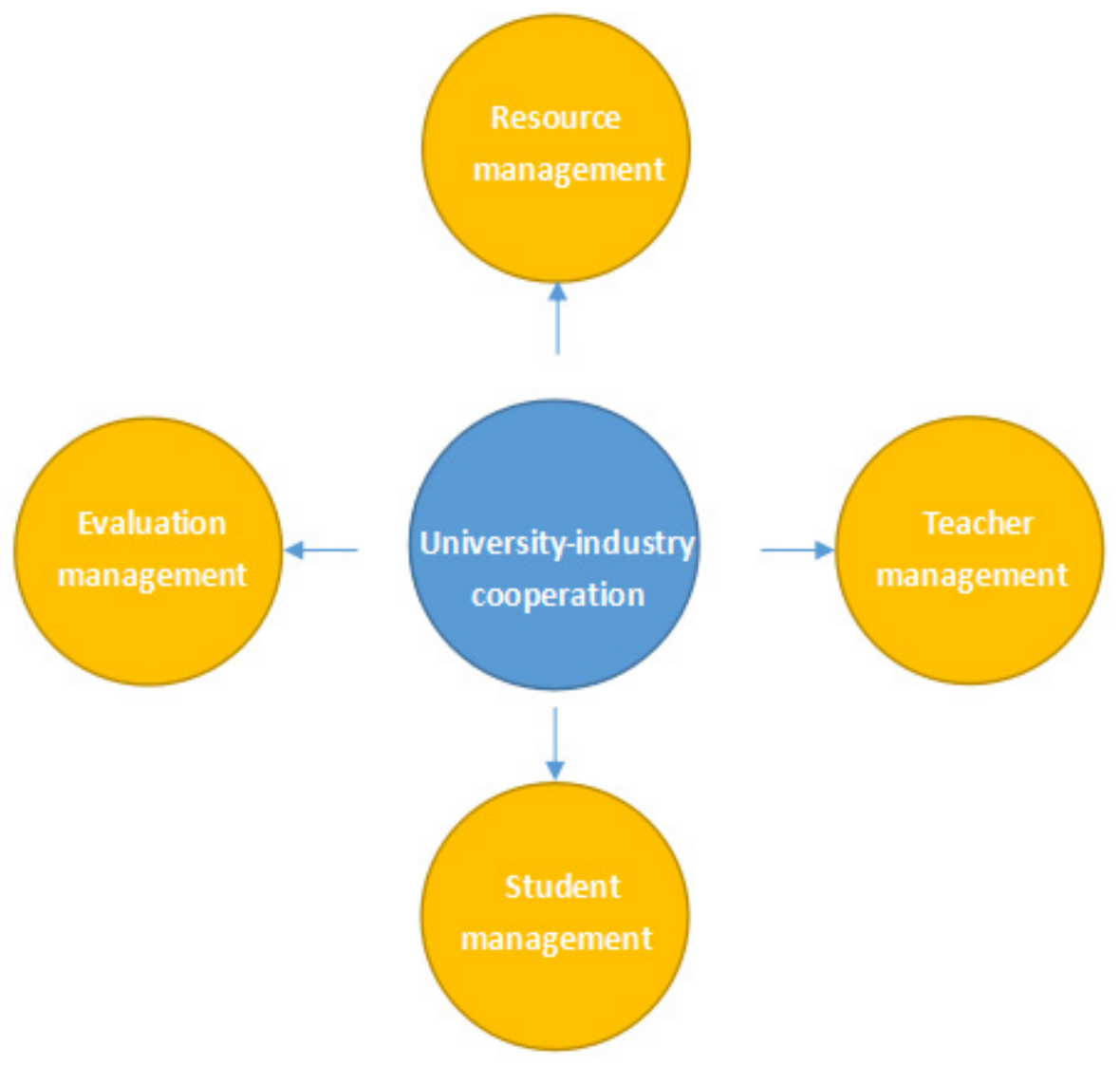

Fig. 1 The components of Al promoting university-industry cooperation

By integrating the components of artificial intelligence to promote university-industry cooperation, the paper concludes that the change of resources andenvironment is the basis of university-industry cooperation.Therefore, starting from theresource and environment of both sides, the paper analyzes the changes in the management of teachers and students and the evaluation of cooperation brought aboutby the development of artificial intelligence, so as to optimize the mode of university-industry cooperation.

(2) Artificial intelligence promotes the innovation and development of resource management in university-industry cooperation

Intelligent analysis: this research attempt from the perspective of resource independent intelligent evolution, the preliminary analysis, the resources of both sides,based on the general process of artificial intelligence, university-enterprise cooperation innovation should focus on the cooperation of both sides in common,thinking a solution to precise education, by creating different types of resources, andhelp the two sides on the resource utilization can intelligent interactive integration,intelligent production and education resource integration, intelligent guide the processof cooperation, so as to improve the effect of cooperation.

Intelligent push: The traditional push methods mainly adopt E-mail push, fileforward and interview, etc., which fails to achieve the personalized and intelligentpush goal.ln addition, the traditional way is easy to cause the problem of lack ofconcentration, lack of focus, which tends to cause waste. 


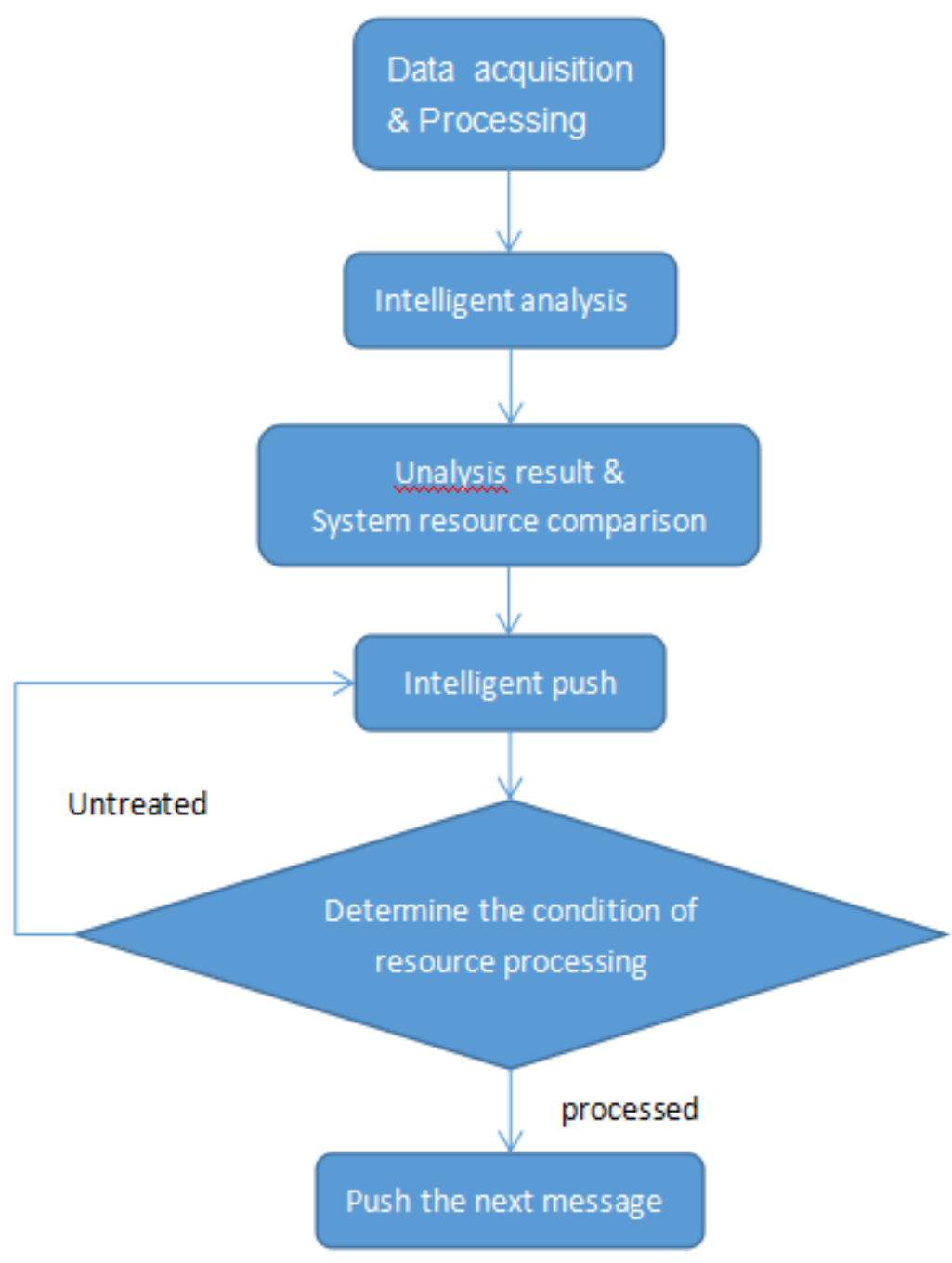

Figure 2 Intelligent push process of teaching resources

The intelligent push can predict and identify the personalized needs and conditionsof users, so as to actively push targeted cooperation resources, so as to provide targeted,personalized and intelligent services for both parties in the era of information flooding,and meet users' demand for easy access to the required information. This is shown in Figure 2.

(3) Research on artificial intelligence promoting innovation and development oftripartite evaluation management

The research focuses on the transformation of university-industry cooperationevaluation mode from manual evaluation to intelligent evaluation, and from standardized evaluation to differential evaluation. The connotation, characteristics andkey technologies of intelligent evaluation and differential evaluation are analyzed, thegeneral process of intelligent evaluation is analyzed, and the implementation suggestions of intelligent evaluation are summarized.It also discusses the application ofartificial intelligence in university-industry cooperative management from two aspects ofscientific decision-making and automatic management.

\section{Key problems to be solved}

(1) Technical support for intelligent environment

First of all, win-win cooperation is the basis of promoting university-industrycooperation.Modern university-industry cooperation has put forward higherrequirements for the construction of intelligent environment, such as intelligentperception demand, diversified service provision, etc.Secondly, IntelliSense is thefoundation of diversified resource push.The development plan of the new generationof artificial intelligence points out that high dynamic, high dimensional and

multi-mode distributed large-scene perception should be realized.

(2) Intelligent university-industry cooperation mode design

School, the machine, the enterprise as the core of the change of teaching mainbody will implement the school with the machine, and machine, schools and enterprises, open and pluralistic interaction more efficient, the development oftechnology, the improvement of the 
environment, the adaptive data resources makes more smooth, more in-depth cooperation process in a timely manner, thecooperation effect is more obvious.From mutual understanding, establishment ofcooperation to in-depth cooperation, intelligent mode is more efficient thantraditional university-industry cooperation in all aspects.Centering on the changesbrought about by the development of artificial intelligence, intelligent university-industry cooperation mode is constructed, as shown in Figure 3 below:

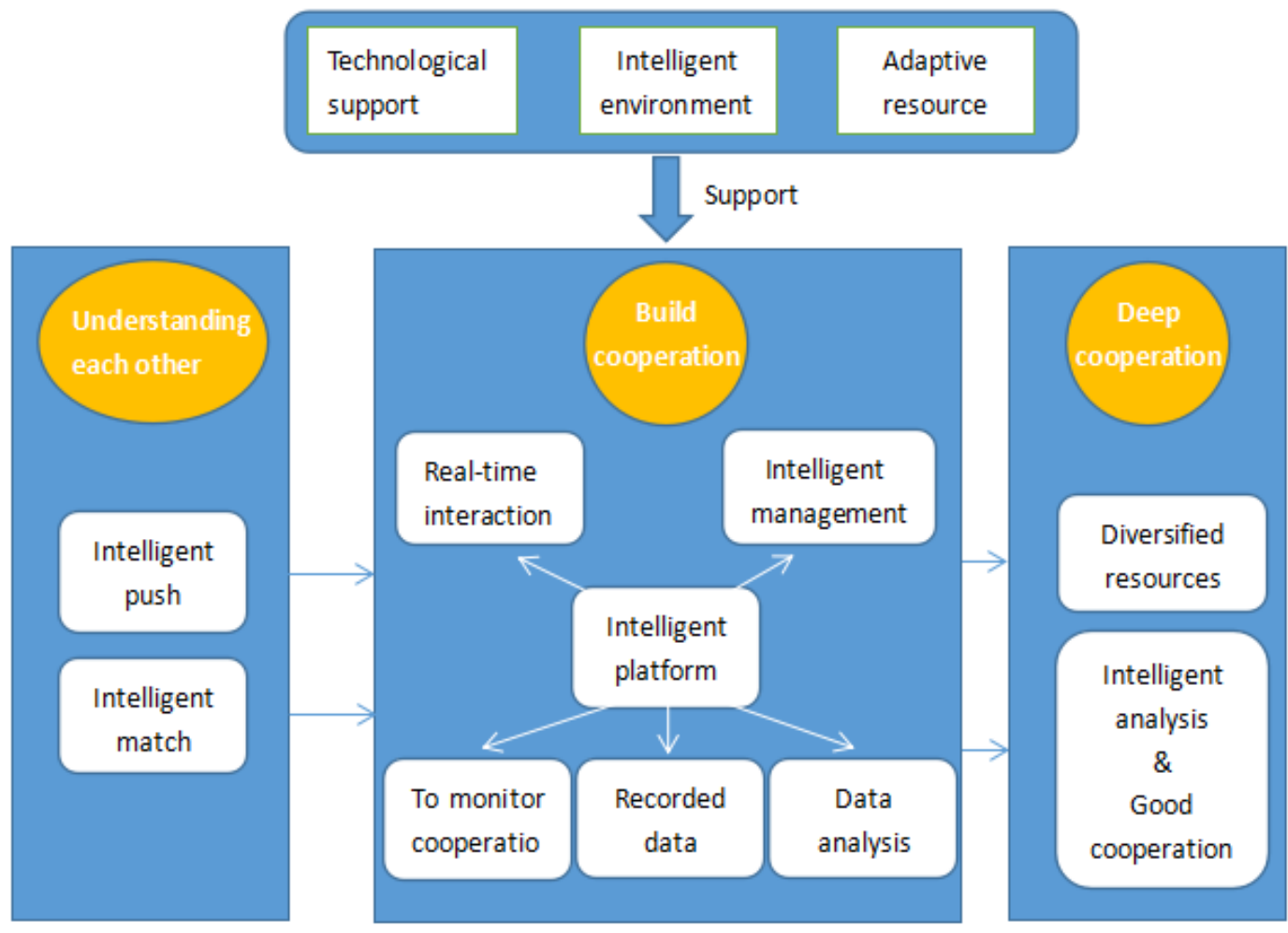

Figure 3 Scenes of intelligent university-industry cooperation mode

\section{Research ideas and technical route}

Study overall following factors: "the research of artificial intelligence applicationdevelopment and the present situation and development trend analysis of the factors:artificial intelligence application and practical case about artificial intelligence to promote the cooperation between colleges and expert interview to extract the artificialintelligence will affect what university-enterprise cooperation links to explore in artificialintelligence promote the optimization of resources, explore the change of artificialintelligence to promote the cooperation between colleges and discusses the innovationof the artificial intelligence to promote the cooperation between colleges" train ofthought. The research technical route is shown in Figure 4 below: 


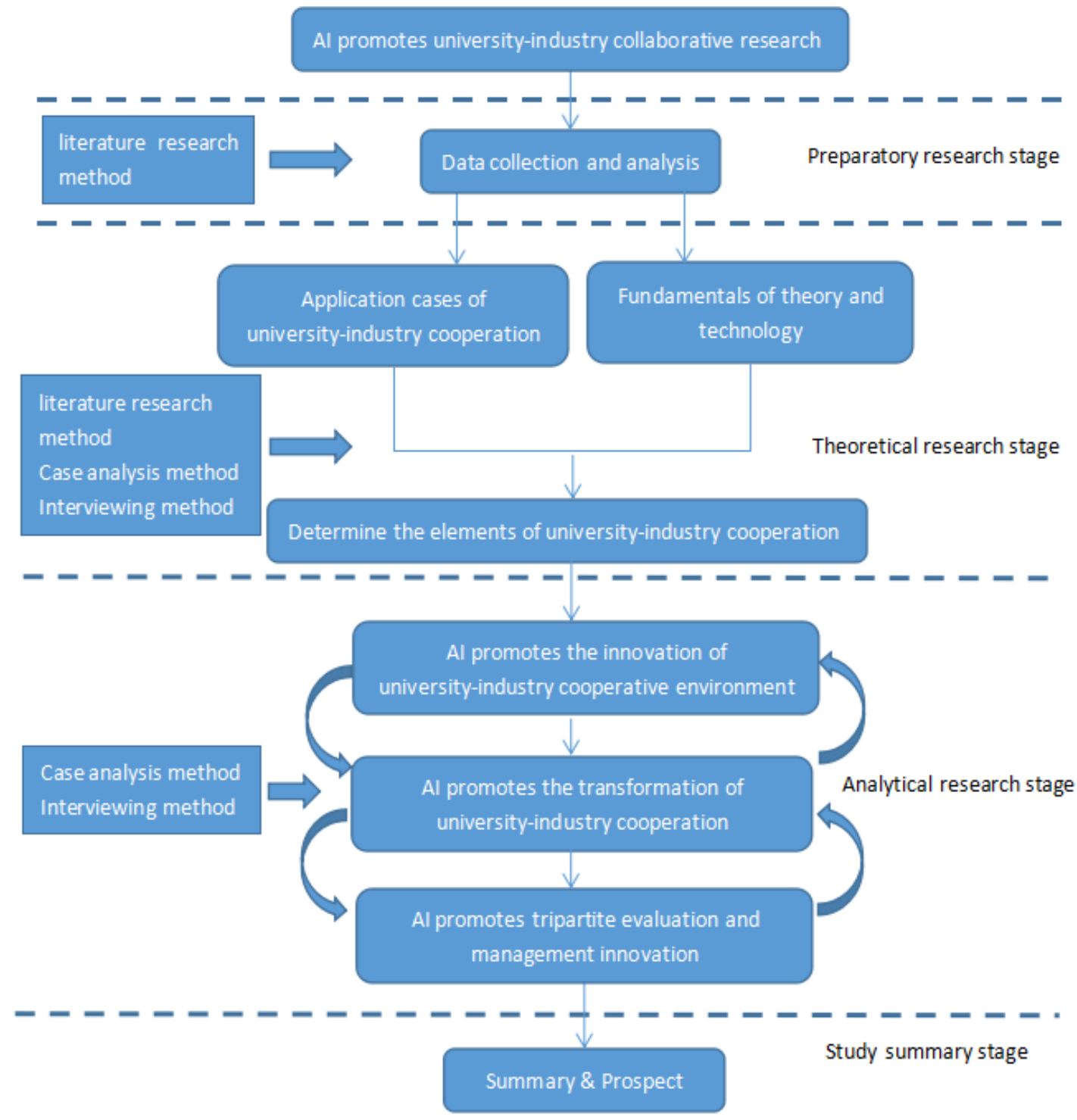

Fig. 4 Research technical route

\section{The conclusion}

There are three innovations in the integration of artificial intelligence into university-industry cooperation: 1 . It can provide a personalized intelligent platform; 2.Constructing intelligent university-industry cooperation mode; 3.Innovative developmentof tripartite evaluation.Technology to promote the integration of schools and enterpriseshas always been the focus of social attention. Artificial intelligence is gradually integrated into the field of education, providing new possibilities to meet the needs ofboth sides for high-quality resources, intelligent environment and diversified modes.Factors artificial intelligence application provides conditions for the smoothimplementation of the intelligent, auxiliary cooperation between both sides of the wholeprocess of artificial intelligence research and analysis of artificial intelligence to cooperation during the specific process to provide support and help to solve thetraditional university-enterprise cooperation existing machinery, inefficiency, lack ofparticipation to promote bilateral cooperation to develop in the direction of intelligent,accurate and diverse.

In a word, in the context of artificial intelligence, the reform, innovation andpractice of university-enterprise cooperation in higher vocational colleges are studiedfrom the overall level, and the research can clarify the thinking of how artificialintelligence technology can better support university-enterprise cooperation.

[Author] Meng Hainie (1983 - ), male, master, lecturer, research direction: computer application technology, digital campus, virtual reality technology.

[Fund project 1] This paper is a phased research result of the quality engineering projectof Guangdong Provincial Department of Education, Research on CollaborativeTalents Training for Computer Specialty Based on the Deep Integration of University and Industry (GDJG2019307). 


\section{References:}

1. Yan Zhiming, Tang Xiaxia,Qin Xuan, Zhang Fei, Duan Yuanmei.Education ArtificialIntelligence (EAl) : Conception,Key Technology and Application Trend -- Analysis of theUnited States "Preparing for the Future of Artificial lntelligence" and "National ArtificialIntelligence R\&D StrategyPlanning" Report[0. Journalof DistanceEducation, 2017(1): 26-35.

2. Tong Yuerong,Chen Jiangping et al. A Study on the Development of InnovativeTalents in Shanghai Jiaotong University $[\mathrm{J}]$. Laboratory Research and Exploration.2020,39(11).

3. Gu Cuifeng, Liu Yating. The design of "double-qualified" teacher training in highervocational colleges based on artificial intelligence []. Vocational Education Forum. 2020, 36(08).

4. Xi-Hai-Xia,Zhao Zhao-Zhe. An analysis of the quality improvement path of newengineering talents training in the era of artificial intelligence -- a case study of computerscience major of Stanford University [J]. Review of Science and Education Development.2020,(00).

5. Ye Xiaotao, Zhao Guangpeng,Lv Aili.Research on the New Mode of CollaborativeEducation of Electronic Information Specialty under the Background of New Engineering-- Taking Henan Polytechnic University as an Example [J]. Modernization of Education.20,7(52).

6. Zhang Weishan. Thinking on Artificial Intelligence Promoting the Development ofSmall and Medium Enterprises [u]. China Development. 2020,20(01).

7. Xiao Xiongziyan, Chu Pengzhi et al.The Construction of university-industry CurriculumBased on Undergraduate Artificial Intelligence of Shanghai Jiao Tong University [u]. Contemporary Educational Practice and Teaching Research.2020,(02)

8. Luckin R, Holmes W. Intelligence Unleashed: An argument for AI in Education [EB/OL]. [2016-11-24].

9. Timms $M$ J. Letting artificial intelligence in education out of the box: educational cobots and smart classrooms[J]. International Journal of Artificial Intelligence in Education,2016(2):701-712.

10. McArthur D, Lewis M, Bishary M. The Roles of Artificial Intelligence in Education: Current Progress and Future Prospects[J]. Journal of Educational Technology,2005(4):42-80.

11. Pinkwart N. Another 25 years of AIED? Challenges and opportunities for intelligent educational technologies of the future[J]. International journal of artificial intelligence in education,2016(2):771-783. 